\title{
Quantificação da biomassa e nutrientes em um povoamento de Eucalyptus dunnii Maiden estabelecido no Bioma Pampa ${ }^{1}$
}

\author{
Grasiele Dick ${ }^{2}$; Mauro Valdir Schumacher ${ }^{3}$; Dione Richer Momolli ${ }^{4}$ Joel Carvalho dos Santos ${ }^{5}$; Aline \\ Aparecida Ludvichak ${ }^{6}$; Claudiney Couto Guimarães ${ }^{7}$; Huan Pablo de Souza ${ }^{8}$
}

Resumo: Estudos relacionados à produção de biomassa e acúmulo de nutrientes são a base para a compreensão da dinâmica nutricional em povoamentos florestais. O objetivo do presente trabalho foi quantificar a biomassa e o estoque de nutrientes, em um povoamento de Eucalyptus dunnii, aos 60 meses de idade, estabelecido em Alegrete, Rio Grande do Sul. A amostragem da biomassa foi realizada a partir de doze árvores, que foram seccionadas ao nível do solo e a biomassa foi fracionada nos componentes: folhas, galhos, casca do tronco e madeira do tronco, com determinação de massa seca e tores de nutrientes. A biomassa total acima do solo foi de $58,76 \mathrm{Mg} \mathrm{ha}^{-1}$, com sequência decrescente de alocação em madeira do tronco > casca do tronco > galhos > folhas. O estoque total de nutrientes foi de 175,5; 18,2; 171; 278,1; 69,1 e 21,5 kg ha-1 de N, P, K, Ca, Mg e $\mathrm{S}$, respectivamente. Ressalta-se a importância da manutenção de resíduos da colheita sobre o solo, a fim de otimizar a ciclagem de nutrientes em função dos altos teores destes contidos nas folhas, casca e galhos.

Palavras - chave: Nutrição florestal; Silvicultura; Ciclagem de nutrientes.

\section{Nutrients and biomass quantification in Eucalyptus dunnii Maiden stand established in Pampa biome}

\begin{abstract}
Studies related to biomass production and accumulation of nutrients, are the basis for understanding the nutritional dynamics in forest stands. The objective of this study was to quantify the biomass and nutrient stocks, in a Eucalyptus dunnii stand, at 60 months old, established in Alegrete, Rio Grande do Sul. The sampling of biomass was taken from twelve trees which were cut at soil level and the fractional biomass components: leaf, branches, trunk bark and stem wood, with dry mass determination and nutrients concentration. The total above ground biomass was $58.76 \mathrm{Mg} \mathrm{ha}^{-1}$, with decreasing sequence in the magnitude of the stem wood > trunk bark > branches > leaves. The total stock of nutrients was $175.5 ; 18.2 ; 171 ; 278.1$; 69.1 and $21.5 \mathrm{~kg} \mathrm{ha}^{-1}$ of N, P, K, Ca, Mg and S, respectively. We emphasize the importance of maintaining of harvest residues in the soil to optimize nutrient cycling due to high levels of these in the leaves, bark and branches.
\end{abstract}

Keywords: Forest nutrition; Silviculture; Nutrient cycling.

\footnotetext{
${ }^{1}$ Recebido em 01.12.2015 e aceito para publicação como artigo científico em 11.03.2016.

${ }^{2}$ Engenheira Florestal, M.Sc., Doutoranda do Programa de Pós-graduação em Engenharia Florestal, Universidade Federal de Santa Maria. E-mail: <grasidick@hotmail.com>.

${ }^{3}$ Engenheiro Florestal, Dr. nat. techn., Professor Titular do Departamento de Ciências Florestais, Universidade Federal de Santa Maria. Email: <mvschumacher@gmail.com>.

${ }^{4}$ Acadêmico, Engenharia Florestal, Universidade Federal de Santa Maria. E-mail: <dionemomolli@gmail.com>.

${ }^{5}$ Engenheiro Florestal, Mestrando do Programa de Pós-graduação em Engenharia Florestal, Universidade Federal de Santa Maria. E-mail: <joelufsm@gmail.com>.

${ }^{6}$ Engenheira Florestal, M.Sc. E-mail: <aline_lud@yahoo.com.br>.

${ }^{7}$ Engenheiro Florestal, M.Sc. Doutorando do Programa de Pós-graduação em Engenharia Florestal, Universidade Federal de Santa Maria. E-mail: <claudiney.guimaraes@storaenso.com>.

${ }^{8}$ Engenheiro Agrônomo, M.Sc. Doutorando do Programa de Pós-graduação em Engenharia Florestal, Universidade Federal de Santa Maria. E-mail: <huan.souza@storaenso.com>.
} 


\section{Introdução}

Em virtude do aumento expressivo da produção florestal no Brasil, tornou-se necessário aperfeiçoar os processos fabris, considerando, sobretudo a produtividade dos povoamentos. Isto se torna possível através da seleção de materiais genéticos adaptados, além da execução de técnicas apropriadas de manejo, tais como adubação, controle de plantas daninhas e intensidade adequada de preparo do solo (GONÇALVES et al., 2015).

Entretanto, na busca por maior rendimento dos povoamentos deve-se considerar, primordialmente, investimentos em práticas conservacionistas, pois os sítios ficam propensos à exaustão nutricional, sendo que, de acordo com Paes et al. (2013), é cada vez maior a preocupação das empresas do setor florestal em adotar práticas pautadas na conservação do solo e da água.

Alternativas advindas dos resultados de pesquisas sobre o ciclo de nutrientes em povoamentos florestais são de fundamental importância, pois possibilitará a previsão de situações que poderiam ser críticas a médio e longo prazo, tanto em relação à produtividade, quanto à qualidade do solo (VIERA et al, 2015). De acordo com Odum (2004), no sistema soloplanta, existem constantes entradas (precipitação e fertilização) e saídas de nutrientes por erosão e, principalmente, exportação dos nutrientes através da colheita de produtos florestais.

A distribuição dos nutrientes nos componentes das árvores tem grande importância na nutrição de plantações, manejadas em rotações curtas e sucessivas. Segundo Schumacher e Viera (2015), o manejo intensivo dos povoamentos de eucaliptos, por exemplo, pode aumentar a produção de biomassa, mas, também, pode aumentar a remoção de nutrientes.

A manutenção do estoque de nutrientes minerais no solo, bem como da produtividade de biomassa das espécies arbóreas de rápido crescimento, como é o caso do gênero Eucalyptus, está ligada diretamente ao processo de ciclagem dos nutrientes. Nesse sentido, o presente estudo teve o objetivo de quantificar a biomassa e o estoque de nutrientes, em um povoamento de Eucalyptus dunnii, aos 60 meses de idade.

\section{Material e métodos}

Situação ecológica

O presente estudo foi conduzido na região da Campanha, fronteira oeste do estado do Rio Grande do Sul, pertencente ao Bioma Pampa, em um local distanciado há aproximadamente $76 \mathrm{~km}$ do município de Alegrete, na Fazenda Sesmaria Santo Inácio, propriedade da empresa StoraEnso Florestal RS Ltda. As coordenadas geográficas centrais da localização do povoamento de Eucalyptus dunnii são $29^{\circ} 47^{\prime}$ sul e $55^{\circ} 17^{\prime}$ oeste, em altitude de $98 \mathrm{~m}$.

Em conformidade com a classificação climática proposta por Matzenauer et al. (2011), o clima da região é do tipo subtemperado úmido, em que os verões podem apresentar período de seca, com temperatura média anual de $18,6^{\circ} \mathrm{C}$ e precipitação média anual de $1.574 \mathrm{~mm}$.

A vegetação que se desenvolve na região da Campanha no Bioma Pampa, é predominantemente composta por campos nativos, caracterizados fisionomicamente pelas gramíneas, entremeados por capões florestais que ocorrem ao longo dos cursos dos rios (BOLDRINI et al., 2010).

$\mathrm{Na}$ área o solo é do tipo Argissolo Vermelho Distrófico típico (EMBRAPA, 2013), de textura arenosa, variando de franco-arenosa a francoargilo-arenosa. A análise do solo da área, descrita em Corrêa et al. (2013), revelou baixo conteúdo de matéria orgânica $(1,0 \%)$ e $\mathrm{pH}$ muito baixo $(4,7)$. Constataram-se ainda teores de $\mathrm{Ca}$ e $\mathrm{Mg}$ baixos, teores de $\mathrm{K}$ e $\mathrm{P}$ muito baixos, teor de $\mathrm{S}$ médio nas camadas de 0-20, 40-60 e 60-80 cm de profundidade e alto teor de $\mathrm{S}$ nas camadas de 20-40 e 80-100 cm de profundidade. A CTC efetiva é média, além de saturação por bases muito baixa e alta saturação por $\mathrm{Al}$, revelando uma baixa fertilidade do solo, situação típica dos solos da região da Campanha no bioma Pampa. 
Características do povoamento

As atividades de implantação do povoamento de Eucalyptus dunnii foram iniciadas em 2008, sobre uma área que estava em processo de degradação do solo, com remoção da cobertura vegetal natural, em função da intensa exploração pastoril. Foram plantadas mudas oriundas de sementes, no espaçamento $2,0 \mathrm{~m} \mathrm{x} \mathrm{3,5} \mathrm{m} \mathrm{entre}$ plantas.

$\mathrm{Na}$ área foi realizado preparo de solo com uma subsolagem, utilizando trator de pneu, em profundidade média de $60 \mathrm{~cm}$, além da fosfatagem na linha, irrigação, adubação de arranque e de cobertura, capinas na linha e entrelinha. Foram aplicados $300 \mathrm{~kg} \mathrm{ha}^{-1}$ de NPK, na formulação 06-30-06 + 0,6 \% de B. A segunda adição do fertilizante foi aos 90 dias após plantio, onde foram aplicados $140 \mathrm{~kg} \mathrm{ha}^{-1} \mathrm{de}$ NPK, utilizando 22-05-20 + 0,2 \% de B + 0,4\% de Zn. A terceira fertilização foi aos 270 dias, com uso de $140 \mathrm{~kg} \mathrm{ha}^{-1}$ de NPK, 22-00-18 + 1,0 $\%$ de $\mathrm{S}+0,3 \%$ de $\mathrm{B}$, aplicada mecanicamente na entrelinha.
Quantificação da biomassa e estoque de nutrientes

Para amostragem da biomassa, realizou-se um inventário onde foram definidas, de forma aleatória, quatro parcelas com dimensão de $20 \mathrm{~m}$ x $21 \mathrm{~m}$ cada. As árvores foram mensuradas no mês de novembro de 2012, ocasião em que o povoamento estava com 60 meses. Todas as árvores inclusas nas parcelas foram medidas quanto ao diâmetro à altura do peito (DAP), com auxílio de fita diamétrica, e altura total (h), com hipsômetro Vertex.

Aos 60 meses o povoamento de Eucalyptus dunnii apresentou parâmetros médios de diâmetro à altura do peito (DAP) de $12 \mathrm{~cm}$, altura (h) de $13 \mathrm{~m}$, área basal (G) $14 \mathrm{~m}^{2} \mathrm{ha}^{-1}$, densidade de 1.143 árvores por hectare e volume com casca de 124,3 $\mathrm{m}^{3} \mathrm{ha}^{-1}$, refletindo assim baixa produtividade de madeira. De posse dos valores dos diâmetros foram estabelecidas quatro classes diamétricas (Tabela 1), sendo que de cada uma destas classes foram abatidas três árvores (limite inferior, médio e superior da classe), resultando em 12 repetições.

Tabela 1 - Classes diamétricas do povoamento de Eucalyptus dunnii aos 60 meses de idade.

Table 1 - Diametric classes of Eucalyptus dunnii stand at 60 months age.

\begin{tabular}{cccc}
\hline \multirow{2}{*}{ Classe } & Limite inferior & Limite central & Limite superior \\
\cline { 2 - 4 } & & $(\mathrm{cm})$ & 6,0 \\
01 & 2,0 & 4,0 & 10,0 \\
02 & 6,1 & 8,0 & 14,0 \\
03 & 10,1 & 12,0 & 18,0 \\
04 & 14,1 & 16,0 & \\
\hline
\end{tabular}

As árvores selecionadas foram cubadas rigorosamente conforme o método de Smalian (PÉLLICO NETTO e BRENA, 1997). Posteriormente realizou-se o fracionamento das árvores nos compartimentos madeira, casca, galhos vivos e folhas, que foram então pesadas, com auxílio de balança de gancho. Para a madeira e a casca foram feitas distribuições de pontos de amostragem ao longo do comprimento do fuste nas posições medianas das secções resultantes da divisão em três partes iguais do mesmo. A ponteira com menos de oito $\mathrm{cm}$ de diâmetro não foi inclusa na amostragem.

Para estimar o estoque de nutrientes, coletaram-se amostras representativas de cada componente, que foram pesadas no campo com balança de precisão. Após a amostragem de aproximadamente $150 \mathrm{~g}$ de massa úmida de cada componente, estas foram encaminhadas para secagem em estufa de circulação de ar a $70^{\circ} \mathrm{C}$, por 72 horas, quando então, foi determinada a massa seca, utilizando balança digital de precisão $(0,01 \mathrm{~g})$.

Nas amostras moídas foram determinadas as 
concentrações de $\mathrm{N}, \mathrm{P}, \mathrm{K}, \mathrm{Ca}, \mathrm{Mg}$ e $\mathrm{S}$, seguindo a metodologia de Tedesco et al. (1995). O cálculo da quantidade de nutrientes, nos compartimentos do Eucalyptus dunnii, foi efetuado por meio do produto da concentração média de nutrientes e a biomassa.

Para estimar a biomassa do povoamento de Eucalyptus dunnii, foi realizada modelagem (Tabela 2) com auxílio do software SAS 13.0 for Windows (1996), considerando o nível de 5\% de probabilidade de erro, utilizando-se o procedimento stepwise.

A modelagem indicou a equação $\ln (y)=b_{0}+$ $b_{1} * \ln ($ dap) para melhor estimar a biomassa dos componentes, pois apresentou melhor ajuste para todos os compartimentos $\left(\mathrm{R} \mathrm{aj}^{2}\right.$ superior a $0,90)$, onde $\ln (y)$ representa o logaritmo natural da biomassa seca (kg por árvore) dos componentes, ln (dap) o logaritmo natural do diâmetro (DAP cm) e $b_{0}$ e $b_{1}$ os coeficientes de regressão.

Tabela 2 - Parâmetros e estatísticas de ajuste do modelo de regressão utilizado para estimar a biomassa do povoamento de Eucalyptus dunnii.

Table 2 - Parameters and statistics of the regression model used to estimate biomass of the Eucalyptus dunnii stand.

\begin{tabular}{|c|c|c|}
\hline Componentes & \multicolumn{2}{|c|}{ Equação } \\
\hline $\begin{array}{c}\text { Folhas } \\
\text { Galhos } \\
\text { Casca } \\
\text { Madeira }\end{array}$ & \multicolumn{2}{|c|}{$\ln y=b_{0}+b_{1} *(\ln . x)$} \\
\hline \multicolumn{3}{|c|}{ Coeficientes e estatísticas de ajuste } \\
\hline $\mathbf{b}_{0}$ & $\mathbf{b}_{1}$ & $\mathbf{R}_{\text {ajust. }}^{2}$ \\
\hline $\begin{array}{l}-4,067957 \\
-4,611727 \\
-3,069934 \\
-2,750768\end{array}$ & $\begin{array}{l}2,057995 \\
2,493024 \\
1,960667 \\
2,469169\end{array}$ & $\begin{array}{l}0,91 \\
0,97 \\
0,94 \\
0,98\end{array}$ \\
\hline
\end{tabular}

Onde: Coeficientes de Regressão ( $\mathrm{b}_{0}$ e $\left.\mathrm{b}_{1}\right)$; Coeficiente de Determinação ajustado ( $\mathrm{R}_{\text {ajust. }}^{2}$.

Análise estatística

Para análise estatística das concentrações de macronutrientes nos componentes da biomassa, utilizou-se o teste de Tukey $(\alpha=5 \%)$, com auxílio do software Assistat versão 7.7 (SILVA e AZEVEDO, 2002). Para o experimento foi utilizado o delineamento inteiramente casualizado, onde cada árvore analisada correspondia a uma repetição, considerando cada componente da biomassa.

\section{Resultados e Discussão}

Produção de biomassa

A produção total de biomassa no povoamento de Eucalyptus dunnii foi de $58,76 \mathrm{Mg} \mathrm{ha}^{-1}$, sendo que, houve 3,55 $\mathrm{Mg} \mathrm{ha}^{-1}(6,04 \%)$ de folhas; 6,45 Mg ha-1 (10,98\%) de galhos; 7,94 Mg ha-1 $(13,51 \%)$ de casca do tronco e $40,82 \mathrm{Mg} \mathrm{ha}^{-1}$ $(69,47 \%)$ de madeira do tronco. Portanto, a prioridade de alocação de biomassa seguiu a sequência decrescente de madeira do tronco > casca do tronco $>$ galhos $>$ folhas.

Poucos estudos são verificados na literatura considerando aspectos relacionados ao Eucalyptus dunnii, sendo um dos mais expressivos o trabalho de Hernández et al. (2009). Neste trabalho os autores avaliaram um povoamento com nove anos, implantado em Algorta no Uruguai, estabelecido sobre solo com elevado conteúdo de matéria orgânica e alta fertilidade, e constataram a produção de biomassa total acima do solo na quantidade de $236 \mathrm{Mg} \mathrm{ha}^{-1}$. A maior biomassa foi verificada na madeira do tronco $\left(172 \mathrm{Mg} \mathrm{ha}^{-1}\right)$, seguida da 
casca do tronco $\left(29 \mathrm{Mg} \mathrm{ha}^{-1}\right)$, galhos (22 $\mathrm{Mg} \mathrm{ha}^{-}$ $\left.{ }^{1}\right)$ e folhas $\left(13 \mathrm{Mg} \mathrm{ha}^{-1}\right)$.

Estes resultados expressam a influência da qualidade do sítio na produção do povoamento florestal, sendo que, em condições de baixa fertilidade do solo, como no caso do presente estudo, a biomassa produzida foi distinta, no entanto, a prioridade de alocação de biomassa seguiu a mesma tendência.

Considerando o gênero Eucalyptus, Schumacher e Caldeira (2001), avaliaram um povoamento de Eucalyptus globulus subespécie maidenii aos quatro anos de idade, onde encontraram biomassa total acima do solo de 83,2 $\mathrm{Mg} \mathrm{ha}^{-1}$.

Já Schumacher et al. (2011), avaliando a biomassa em povoamento de Eucalyptus spp. com 4 anos de idade, implantado sob Argissolo, verificaram resultados aproximados ao deste estudo para os compartimentos folhas $(3,96 \mathrm{Mg}$ $\left.\mathrm{ha}^{-1}\right)$ e galhos $\left(8,57 \mathrm{Mg} \mathrm{ha}^{-1}\right)$. Para a madeira do tronco $\left(22,5 \mathrm{Mg} \mathrm{ha}^{-1}\right)$ e casca do tronco $(3,46 \mathrm{Mg}$ $\mathrm{ha}^{-1}$ ) houveram menores quantidades de biomassa em relação ao presente estudo. Os autores encontraram 44,55 $\mathrm{Mg} \mathrm{ha}^{-1}$ aos quatro anos e apontam à tendência de aumento da biomassa da madeira, em função do avanço da idade do povoamento.

Avaliando a biomassa em um povoamento de Eucalyptus urophylla $x$ Eucalyptus globulus, com 10 anos de idade, Viera et al. (2013) constataram que $93,7 \%$ da biomassa estava alocada nos componentes madeira e casca, sendo que, para a madeira a grandeza foi de $167,1 \mathrm{Mg}$ $\mathrm{ha}^{-1}$ na casca $18,9 \mathrm{Mg} \mathrm{ha}^{-1}$, galhos com $8,8 \mathrm{Mg}$ $\mathrm{ha}^{-1}$ e folhas com 3,6 Mg ha-1, revelando novamente a tendência de acúmulo de biomassa na madeira do tronco, em função do aumento da idade do povoamento.

Já no Distrito Federal, Gatto et al. (2014) estimaram a biomassa de povoamento de Eucalyptus urophylla $x$ Eucalyptus grandis, com cinco anos de idade, implantado em solo de baixa fertilidade e constataram resultados semelhantes ao presente estudo, com $57,36 \mathrm{Mg}$ ha $^{-1}$ de madeira, 8,08 $\mathrm{Mg} \mathrm{ha}^{-1}$ de galhos, $5,03 \mathrm{Mg}$ ha $^{-1}$ de casca, totalizando $69,19 \%$ da biomassa total e 4,02 $\mathrm{Mg} \mathrm{ha}^{-1}$ de folhas, enfatizando o reflexo da qualidade do sítio sobre a produtividade de um povoamento florestal.

Nutrientes nos componentes das árvores

Quanto a concentração de nutrientes no povoamento, pôde-se verificar diferença significativa $(p \leq 0,05)$ entre os elementos, considerando os distintos componentes da árvore (Tabela 3). Com exceção do Ca, que está em maior expressão na casca do tronco e galhos, todos os nutrientes estão mais concentrados nas folhas.

O mesmo padrão foi encontrado por Viera et al. (2013), que enfatizam à tendência da maioria dos nutrientes de concentrar-se nas estruturas mais novas da planta, devido a maior atividade metabólica nas folhas. Além disto, nestes locais é que se encontram a maioria das células vivas, que são responsáveis pela fotossíntese e pela transpiração.

A magnitude de concentração dos diferentes nutrientes na biomassa total acima do solo apresentou a seguinte ordem decrescente: $\mathrm{Ca}>$ $\mathrm{N}>\mathrm{K}>\mathrm{Mg}>\mathrm{S}>\mathrm{P}$. Com exceção do enxofre, que não foi analisado no trabalho de Schumacher e Caldeira (2001), a ordem de alocação dos nutrientes foi a mesma para o Eucalyptus globulus subespécie maidenii, aos quatro anos de idade.

Já Viera et al. (2012) encontraram sequência semelhante para o Eucalyptus urophylla $x$ Eucalyptus globulus, no entanto, o enxofre foi o elemento presente em menores quantidades. Em contrapartida, Gatto et al. (2014) não obtiveram a mesma conformação, sendo então $\mathrm{N}>\mathrm{K}>\mathrm{Ca}$ $>\mathrm{S}>\mathrm{Mg}>\mathrm{P}$, para Eucalyptus urophylla $x$ Eucalyptus grandis, em um povoamento de cinco anos.

O cálcio é um nutriente de baixa mobilidade no floema, presente principalmente nos elementos lignificados, como a casca, galhos, raízes e em folhas maduras (MARENCO e LOPES, 2009). Maiores concentrações de Ca, na casca do tronco e galhos, também foi observada nos trabalhos de Viera et al. (2013), para o híbrido Eucalyptus urophylla $x$ Eucalyptus globulus e de Schumacher e Poggiani (1993), 
que constataram o mesmo comportamento para

Eucalyptus grandis e Eucalyptus torelliana.

as espécies Eucalyptus camaldulensis,

Tabela 3 - Concentrações médias de nutrientes $\left(\mathrm{g} \mathrm{kg}^{-1}\right)$ nos tecidos do povoamento de Eucalyptus dunnii, aos 60 meses de idade.

Table 3 - Mean concentrations of nutrients $\left(\mathrm{g} \mathrm{kg}^{-1}\right)$ in the tissues of Eucalyptus dunnii stand, at 60 months old.

\begin{tabular}{ccccccc}
\hline \multirow{2}{*}{ Componente } & $\mathbf{N}$ & $\mathbf{P}$ & $\mathbf{K}$ & $\mathbf{C a}$ & $\mathbf{M g}$ & $\mathbf{S}$ \\
\cline { 2 - 7 } & \multicolumn{7}{c}{$\mathrm{g} \mathrm{kg}^{-1}$} \\
\hline \multirow{2}{*}{ Folhas } & $17,38 \mathrm{a}$ & $1,12 \mathrm{a}$ & $6,27 \mathrm{a}$ & $9,85 \mathrm{~b}$ & $2,89 \mathrm{a}$ & $1,14 \mathrm{a}$ \\
& $(18,20)$ & $(21,43)$ & $(13,37)$ & $(20,20)$ & $(11,42)$ & $(20,0)$ \\
\hline \multirow{2}{*}{ Galhos } & $3,93 \mathrm{~b}$ & $0,35 \mathrm{c}$ & $4,43 \mathrm{c}$ & $9,78 \mathrm{~b}$ & $1,79 \mathrm{~b}$ & $0,36 \mathrm{~b}$ \\
& $(20,23)$ & $(37,14)$ & $(13,25)$ & $(29,65)$ & $(22,46)$ & $(26,39)$ \\
\hline \multirow{2}{*}{ Madeira do tronco } & $1,47 \mathrm{c}$ & $0,19 \mathrm{c}$ & $1,94 \mathrm{~d}$ & $1,26 \mathrm{c}$ & $0,60 \mathrm{c}$ & $0,31 \mathrm{~b}$ \\
& $(26,72)$ & $(31,58)$ & $(16,60)$ & $(28,57)$ & $(28,33)$ & $(48,39)$ \\
\hline \multirow{2}{*}{ Casca do tronco } & $3,59 \mathrm{~b}$ & $0,54 \mathrm{~b}$ & $5,16 \mathrm{~b}$ & $16,2 \mathrm{a}$ & $2,88 \mathrm{a}$ & $0,31 \mathrm{~b}$ \\
& $(12,26)$ & $(33,33)$ & $(13,95)$ & $(25,55)$ & $(12,15)$ & $(12,58)$ \\
\hline
\end{tabular}

*As médias seguidas pela mesma letra, na coluna, dentro de cada componente, não diferem estre si pelo teste de Tukey a 5\% de probabilidade. **Coeficiente de variação entre as repetições (valor entre parênteses).

$\mathrm{Na}$ madeira do tronco foram verificadas as menores concentrações de todos os elementos, sendo que tal expressão ocorre em função da translocação e pouco concentração de nutrientes neste componente (MARENCO e LOPES, 2009). Já nas folhas, os elementos como nitrogênio, fósforo, magnésio e potássio apresentaram maiores valores, em função da alta mobilidade destes nutrientes. Isto também foi verificado por Gatto et al. (2014), para o híbrido Eucalyptus urophylla $x$ Eucalyptus grandis, onde o teor de nitrogênio foi de $13,55 \mathrm{~g} \mathrm{~kg}^{-1}$, de fósforo $1,33 \mathrm{~g} \mathrm{~kg}^{-1}$, magnésio $2,44 \mathrm{~g} \mathrm{~kg}^{-1} \mathrm{e}$ potássio $8,52 \mathrm{~g} \mathrm{~kg}^{-1}$, resultados semelhantes ao deste estudo.

O fósforo e o enxofre foram os elementos encontrados em menores concentrações, o que ocorreu em virtude da baixa disponibilidade destes nutrientes no solo. Segundo Schumacher e Caldeira (2001), em estudo com Eucalyptus globulus subespécie maidenii aos quatro anos de idade e Hernández et al. (2009) avaliando a espécie Eucalyptus dunnii aos nove anos, também constataram menores concentrações destes elementos.

Em plantios de eucalipto no Congo, estabelecidos sobre solo de baixa fertilidade, Laclau et al. (1999) avaliaram a biomassa do primeiro até o sétimo ano do povoamento e verificaram que, aos cinco anos houve aumento do teor de nitrogênio nas folhas. A tendência de redução da concentração de nutrientes nas folhas, do primeiro ao quinto ano, ocorreu para os demais macronutrientes ( $\mathrm{P}, \mathrm{K}, \mathrm{Ca} \mathrm{e} \mathrm{Mg}$ ), sendo que, houve estabilidade nos demais compartimentos (galhos e casca do tronco).

A análise do estoque de macronutrientes (Tabela 4) revelou que, apesar da casca do tronco contribuir com apenas 13,5\% do total da biomassa, esta possui a maior quantidade de cálcio, sendo este o nutriente mais abundante. A madeira do tronco, que é responsável pela maior proporção de biomassa, teve maior acúmulo de potássio $(46,31 \%)$, enxofre $(58,91 \%)$ e magnésio $(35,41 \%)$, além de altas quantidades de nitrogênio $(34,18 \%)$.

Já nas folhas, onde houve menor biomassa $(5,3 \%)$, o estoque de nitrogênio foi superior aos demais componentes, representando $35,14 \%$ do total deste nutriente. A demanda por nitrogênio é maior nas folhas, em função das exigências para o funcionamento do aparato fotossintético (PRADO, 2008), composição e ativação de enzimas, em consequência, este é o elemento mais expressivo e indispensável nas práticas de fertilização em plantações comerciais de 
eucalipto.

A magnitude de estoque de nutrientes, considerando a quantidade presente na biomassa total, segue a ordem decrescente: $\mathrm{Ca}>\mathrm{N}>\mathrm{K}>$ Mg $>$ S > P. Já Viera et al. (2012) avaliaram a biomassa total acima do solo em Eucalyptus urophylla $x$ Eucalyptus grandis, aos 16 meses, constatando a sequência: $\mathrm{N}>\mathrm{Ca}>\mathrm{K}>\mathrm{Mg}>\mathrm{P}$ $>\mathrm{S}$.

Tabela 4 - Estoque de nutrientes na biomassa das árvores de Eucalyptus dunnii, aos 60 meses.

Table 4 - Nutrients stock in the of Eucalyptus dunnii trees, at 60 months old.

\begin{tabular}{ccccccc}
\hline \multirow{2}{*}{ Componente } & $\mathbf{N}$ & $\mathbf{P}$ & $\mathbf{K}$ & $\mathbf{C a}$ & $\mathbf{M g}$ & $\mathbf{S}$ \\
\cline { 2 - 7 } & \multicolumn{7}{c}{$\mathrm{kg} \mathrm{ha}^{-1}$} \\
Folhas & 61,70 & 3,92 & 22,25 & 34,96 & 10,25 & 4,04 \\
Galhos & 25,34 & 2,25 & 28,57 & 63,08 & 11,54 & 2,32 \\
Madeira do tronco & 60,00 & 7,75 & 79,19 & 51,43 & 24,49 & 12,65 \\
Casca do tronco & 28,50 & 4,28 & 40,97 & 128,62 & 22,86 & 2,46 \\
Total & $\mathbf{1 7 5 , 5}$ & $\mathbf{1 8 , 2}$ & $\mathbf{1 7 0 , 1}$ & $\mathbf{2 7 8 , 1}$ & $\mathbf{6 9 , 1}$ & $\mathbf{2 1 , 5}$ \\
\hline
\end{tabular}

Ressalta-se que a distribuição dos nutrientes nos compartimentos das árvores tem grande importância na nutrição de povoamentos florestais manejados em rotações sucessivas. $\mathrm{O}$ manejo intensivo das plantações de eucaliptos (plantios adensados e rotações curtas), por exemplo, pode aumentar a produção de biomassa, mas também pode intensificar a remoção de nutrientes (VIERA et al., 2013).

\section{Conclusões}

A biomassa total acima do solo foi de 58,76 $\mathrm{Mg} \mathrm{ha}^{-1}$, com sequência decrescente de alocação em madeira do tronco $>$ casca do tronco $>$ galhos $>$ folhas. O estoque total de nutrientes foi de 175,$5 ; 18,2 ; 171 ; 278,1 ; 69,1$ e $21,5 \mathrm{~kg} \mathrm{ha}^{-1}$ de N, $\mathrm{P}, \mathrm{K}, \mathrm{Ca}, \mathrm{Mg}$ e $\mathrm{S}$, respectivamente.

A biomassa estimada para o povoamento de Eucalyptus dunnii foi semelhante aos resultados obtidos em vários estudos sobre o gênero Eucalyptus, sendo que, a qualidade química do solo é determinante na quantidade de biomassa produzida.

Em função das altas concentrações de nutrientes nas folhas, casca, galhos, ressalta-se a importância da manutenção de resíduos vegetais no solo após a colheita florestal, a fim de otimizar a ciclagem de nutrientes.

\section{Agradecimentos}

Os autores agradecem à empresa StoraEnso pelo apoio financeiro e disponibilidade de área experimental.

\section{Referências Bibliográficas}

BOLDRINI, I.I. et al. Bioma Pampa: diversidade florística e fisionômica. Porto Alegre/RS, Pallotti, 2010. 64p.

CORRÊA, R. S.; SCHUMACHER, M. V.; MOMOLLI, D. R. Deposição de serapilheira e macronutrientes em povoamento de Eucalyptus dunnii Maiden sobre pastagem natural degradada no Bioma Pampa. Scientia Forestalis (IPEF), v. 41, p. 65-74, 2013.

EMPRESA BRASILEIRA DE PESQUISA AGROPECUÁRIA - EMBRAPA. Sistema brasileiro de classificação de solos. $3^{\mathrm{a}}$ ed. Rio de Janeiro/RJ, Embrapa Solos, 2013 
GATTO, A. et al. Ciclagem e balanço de nutrientes no sistema solo-planta em um plantio de Eucalyptus sp. no Distrito Federal. R. Bras. Ciência do Solo, v. 38, p. 879-887, 2014.

GONÇALVES, J.L.M. et al. Caracterização edafoclimática e manejo de solos das áreas com plantações de eucalipto. In: SCHUMACHER, M.V.; VIERA, M. Silvicultura do Eucalipto no Brasil. Santa Maria, Ed. UFSM. 2015. 308p.

HERNÁNDEZ, J. et al. Nutrient export and harvest residue decomposition patterns of a Eucalyptus dunnii Maiden plantation in temperate climate of Uruguay. Forest Ecology and Management. v 258, p. 92-99, 2009.

LACLAU, J.-P; BOUILLET, J.P.; RANGER, J. Dynamics of biomass and nutrient accumulation in a clonal plantation of Eucalyptus in Congo. Forest Ecology and Management. v 128, p. 181-196, 1999.

MARENCO, R.A.; LOPES, N.F. Fisiologia vegetal: fotossíntese, respiração, relações hídricas e nutrição mineral. 3 ed. Viçosa/MG, UFV, 2009. 486p.

MATZENAUER, R.; RADIN, B.; ALMEIDA, I. R. (Ed.). Atlas Climático: Rio Grande do Sul. Porto Alegre: Secretaria da Agricultura Pecuária e Agronegócio; Fundação Estadual de Pesquisa Agropecuária (FEPAGRO), 2011.

ODUM, E.P. Fundamentos de Ecologia. 7. ed. Lisboa, Fundação Calouste Gulbenkian, 2004. 928p.

PAES, F.A.S.V. et al. Impacto do manejo dos resíduos da colheita, do preparo do solo e da adubação na produtividade de eucalipto. R. Bras. Ciência do Solo, v 37, p. 1081-1090, 2013.

PÉlliCO NETTO, S.; BRENA, D.A. Inventário Florestal. Santa Maria/RS, FSM/CEPEF/FATEC, 1997. 315p.
PRADO, R.M. Nutrição de plantas. São Paulo/SP, UNESP, 2008. 407p.

SAS - STATISTICAL ANALYSIS SYSTEM. Sistema integrado de aplicações para análise estatística de dados. 1996.

SCHUMACHER, M.V.; VIERA, M. Ciclagem de nutrientes em plantações de eucalipto. In: SCHUMACHER, M.V.; VIERA, M. Silvicultura do Eucalipto no Brasil. Santa Maria, Ed. UFSM. 2015. 308p.

SCHUMACHER, M.V.; WITSCHORECK, R.; CALIL, F.N. Biomassa em povoamentos de Eucalyptus spp. de pequenas propriedades rurais em Vera Cruz, RS. Ciência Florestal. v 2, p. 1722, 2011.

SCHUMACHER, M.V.; CALDEIRA, M.V.W. Estimativa da biomassa e do conteúdo de nutrientes de um povoamento de Eucalyptus globulus (labillardiere) subespécie maidenii. Ciência Florestal. v 11, p. 45-53, 2001.

SCHUMACHER, M.V.; POGGIANI, F. Produção de biomassa e remoção de nutrientes em povoamentos de Eucalyptus camaldulensis Dehnh, Eucalyptus grandis Hill ex Maiden e Eucalyptus torelliana f. Muell, plantados em Anhembi, SP. Ciência Florestal. v. 3, p. 9-18, 1993.

SILVA, F. de S.; AZEVEDO, C.A.V. de. Versão do programa computacional ASSISTAT para o sistema operacional Windows. Rev. Bras. Produção Agroindustrial, v 4, n. 1, p. 71-78, 2002.

TEDESCO, M.J. et al. Análise de solo, plantas e outros materiais. 2.ed. Porto Alegre, UFRGS, 1995. 174p.

VIERA, M. et al. Biomassa e nutrientes em um povoamento de Eucalyptus urograndis na Serra do Sudeste-RS. Semina: Ciências Agrárias. v 33, p. 2481-2490, 2012. 
VIERA, M.; SCHUMACHER, M.V.; CALDEIRA, M.V.W. Biomassa e exportação de nutrientes pela colheita do eucalipto. In: SCHUMACHER, M.V.; VIERA, M. Silvicultura do Eucalipto no Brasil. Santa Maria, Ed. UFSM. 2015. 308p.

VIERA, M. et al. Biomassa e nutrientes em um povoamento de Eucalyptus urophylla $x$ Eucalyptus globulus, em Eldorado do Sul-RS. Ecologia e Nutrição Florestal,v 1, p.1-13, 2013. 